\title{
NIH considers updating the Guide
}

On 9 November 2005, the National Institutes of Health (NIH) Office of Scientific Affairs, Office of Extramural Research, Office of the Director issued a Request for Information (RFI) on standards for the care and use of laboratory animals ${ }^{1}$. The purpose of this request was to determine whether NIH should update the 1996 edition of the Guide for the Care and Use of Laboratory Animals (Guide).

Originally published in 1963, the Guide has been revised several times; the most recent version was released in 1996.

All domestic institutions receiving $\mathrm{NIH}$ grants and conducting research on live, vertebrate animals must adhere to the Public Health Service Policy on Humane Care and Use of Laboratory Animals (PHS Policy). PHS Policy requires that institutions use the Guide as the basis for developing their ani- mal care and use programs. In addition, the Association for Assessment and Accreditation of Laboratory Animal Care International (AAALAC International) evaluates animal care and use programs for compliance with the standards set forth in the Guide.

$\mathrm{NIH}$ is soliciting new information related to four chapters in 1996 Guide: institutional policies and responsibilities; animal environment, housing, and management; veterinary medical care; and physical plant. Specifically, they request new scientific information on the following topics:

- "The macro- and micro environment of animal facilities;

- "Housing for laboratory animals, including space, temperature and humidity, ventilation, acoustics, and illumination;

- "Structural and social environment of animals;
- "Husbandry, sanitation and pest control;

- "Disease and disease manifestations in laboratory animals;

- "Population management of genetically modified animals;

- "Physical plant standards; and

- "The topics listed in Appendix A, Selected Bibliography, of the 1996 Guide."

Respondents should submit three copies of their responses, identified with RFI number NOT-OD-06-011, to Dr. Margaret Snyder, Director, Office of Scientific Affairs, Office of Extramural Research, OD, NIH, 6705 Rockledge I, Ste. 4184, MSC 7983, Bethesda, MD 20892 no later than 28 February 2006.

1. NIH. NOT-OD-06-011. Request for Information (RFI): Standards for the care and use of laboratory animals. (9 November 2005). http:// grants.nih.gov/grants/guide/notice-files/NOT0D-06-011.html

\section{European Commission, industry groups agree to reduce animal testing}

In a 7 November 2005 meeting in Brussels, Belgium, the European Commission and industry associations from the pharmaceutical, chemical, cosmetics, and biotechnology sectors signed a joint declaration to promote alternative approaches to animal testing, and the development and validation of replacement, reduction, and refinement methods ${ }^{1,2}$.

According to Janez Potočnik, European Commissioner for Science and Research, "The agreement with different industry sectors is a major step forward in making validated alternative methods avail- able. We will support the partnership by increasing our efforts to support research, development and evaluation of alternative testing methods under the new Research Framework Programme ${ }^{2}$."

A task force will design concrete activities during the first quarter of 2006, to promote the development, validation and regulatory acceptance of alternative approaches, such as:

- "Mapping of research activities and current strategies;

- "Cooperation in research;

• "Development of alternative approaches, including intelligent testing strategies;
- "Facilitate the validation process by available knowledge; and

- "Practical mechanisms to facilitate the regulatory acceptance process of alternative approaches ${ }^{2}$."

1. European Partnership to Promote Alternative Approaches to Animal Testing: 3 Rs Declaration. http://pharmacos.eudra.org/F3/cosmetic/doc/ Declaration3Rs_add.pdf.

2. EUROPA Press Releases. Reducing animal testing: Commission agrees partnership with industry. (7 November 2005). http:// europa.eu.int/rapid/pressReleasesAction. do?reference $=$ IP $/ 05 / 1375 \&$ format=HTML\& aged $=0$ \&language $=E N \&$ guilanguage $=e n$. 